Badmus, K.O. et al. (2017). Treatment of persistent organic pollutants in wastewater using hydrodynamic cavitation in synergy with advanced oxidation process. Environmental Science and Pollution Research. http://dx.doi.org/10.1007/s11356-017-1171-z

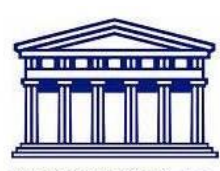

UNIVERSITY of the WESTERN CAPE

\title{
Treatment of persistent organic pollutants in wastewater using hydrodynamic cavitation in synergy with advanced oxidation process
}

Kassim Olasunkanmi Badmus, Jimoh Oladejo Tijani, Emile Massima and Leslie Petrik

\begin{abstract}
Persistent organic pollutants (POPs) are very tenacious wastewater contaminants. The consequences of their existence have been acknowledged for negatively affecting the ecosystem with specific impact upon endocrine disruption and hormonal diseases in humans. Their recalcitrance and circumvention of nearly all the known wastewater treatment procedures are also well documented. The reported successes of POPs treatment using various advanced technologies are not without setbacks such as low degradation efficiency, generation of toxic intermediates, massive sludge production, and high energy expenditure and operational cost. However, advanced oxidation processes (AOPs) have recently recorded successes in the treatment of POPs in wastewater. AOPs are technologies which involve the generation of $\mathrm{OH}$ radicals for the purpose of oxidising recalcitrant organic contaminants to their inert end products. This review provides information on the existence of POPs and their effects on humans. Besides, the merits and demerits of various advanced treatment technologies as well as the synergistic efficiency of combined AOPs in the treatment of wastewater containing POPs was reported. A concise review of recently published studies on successful treatment of POPs in wastewater using hydrodynamic cavitation technology in combination with other advanced oxidation processes is presented with the highlight of direction for future research focus.
\end{abstract}

\section{Introduction}

The combinations of effluents from one or more of industrial, domestic, agricultural, institutional and commercial practices constitute wastewater. The concept is very important in water resource management because it allows economically feasible reuse or controlled discharge of toxic waste into the environment. Efficient wastewater management, availability of potable water and good sanitation are important ingredients in the actualisation of Millennium Development Goals (MDG) (UNESCO 2012). The major components of waste-water such as organic pollutants, toxic metals, micro-pollutants, plant nutrients and pathogenic microorganisms can cause serious health and environmental problems when released untreated (Corcoran et al. 2010). Meanwhile, only a small volume of the produced wastewater can be adequately treated with conventional treatment facilities (Frenken and Gillet 2012). The consequence of this is the rapid growth of deoxygenated dead zones across the oceans, seas and lakes with grievous impact on living organisms and their environment. 
Evolution of gases (from the dead zone) such as methane and nitrous oxide which cause ozone layer depletion as well as chemical contamination and microbial pollution may partially be responsible for the recent upsurge in poor global health (UNESCO 2012). Besides, the majority of the mega cities are adversely affected because of their high population status and location which is generally on the coastal line with little or no means of adequately disposing effluents from toilets, kitchens and baths (Corcoran et al. 2010).

Apparently, wastewater can originate from a discrete and identifiable point source or from a diffuse and difficult to control non-point source. Domestic and industrial wastewaters are very common point sources while agricultural wastewater predominate the non point sources of contamination. Domestic wastewater, either black water (excreta, urine and faecal sludge) or grey water (kitchen and bathing wastewater), has a significant concentration of excreted pathogens, especially in high epidemic regions. These pathogenic organisms are responsible for the preventable death of about 1.45 million people annually (Pandey et al. 2014). The wastewater management system must therefore be efficient for disease prevention and control among many other functions. Besides, diffused and end of pipe pollutants are mostly sourced from agricultural wastewater. Agricultural practices account for the highest percentage of global water use. Wastewater from agricultural sources is difficult to quantify because of its diffused nature. However, it has been recognised as a major global contributor of pollutants (OECD 2011). Industrial wastewater contains a significant number of persistent organic pollutants, toxic chemicals, heavy metals and micro-pollutants. Ninety percent of industrial wastewater is intentionally dumped untreated in developing countries (Corcoran et al. 2010). The success stories in some countries are based on clear allocation of responsibilities for wastewater managers and strict adherence to the principles of urban wastewater treatment directives (DEFRA 2012). Permits or consents can also be issued based on the quantity and quality of waste to be discharged and some substances (arsenic, mercury, cadmium, selected pesticides, cyanides and a number of complex organic compounds) are banned completely. The huge amount of wastewater generated in manufacturing companies and the household must be treated to ensure effective reclamation and reuse of the scarce water resources for profitability and efficient management. In view of this, investment in low energy, environmentally friendly and cost-effective wastewater treatment technology can no longer be delayed. The major focus of contaminant removal is based on organic matter which is primarily measured by oxygen demand. Chemical oxygen demand (COD) is the amount of dissolved oxygen required by a chemical oxidising agent for the oxidation of organic content of the treated water. Meanwhile, biochemical oxygen demand (BOD) measures the dissolved oxygen used in the oxidation of organic matter by microorganisms. COD is higher in magnitude than BOD because there are many organic chemicals that cannot be oxidised by microorganisms but can be easily oxidised by chemicals. The oxygen used in the incineration (physical oxidation) of organic matter in the treated water is measured by total oxygen demand (TOD) while the amount of organic carbon remaining after incineration of the treated water is termed total organic carbon (TOC). This paper examines the existence of persistent organic pollutants (POPs) contamination in wastewater, its effect on humans, the success and failure of conventional wastewater treatment to degrade the POPs in wastewater. Furthermore, the attempt made through the development of various forms of advanced treatment options in 
removing these POPs and the opportunities offered by the use of heterogeneous Fenton processes in hybrid combinations with hydrodynamic cavitation are also reviewed.

\section{Persistent organic pollutants}

Persistent organic pollutants are a group of bioaccumulative chemicals with the propensity for long distance transportation and long retention time in the environmental media without degrading into less toxic forms. They are contaminants of emerging concern (CEC) due the recent increase in the awareness of their biological and economic importance. Especially worrying is the negative health impact and endocrine-disrupting role of a number of these compounds (Clara et al. 2005; Kiparissis et al. 2003). The diverse sources and volumes of POPs are increasing while fresh water is consequently depreciating in both quality and quantity (Hossain et al. 2012). The sources of POPs include anthropogenic, agricultural and industrial. Pharmaceuticals, personal care products, hormones, industrial chemicals, organic dyes and pesticides are known examples of POPs. These chemicals are responsible for disruption of the immune system, cause cancer, central nervous system and reproductive disorders. Initially, 12 chemicals were already recognised at Stockholm convention for their responsibility for causing adverse effects on human and ecosystem (Table 1) (Krapcheva 2006). Contamination of water by POPs constitutes a great environmental liability for the current generation due to their resistance to photolytic, chemical and biological degradation and their harmful impact on abiotic and biotic species (Krapcheva 2006). POPs are capable of bioaccumulation and biomagnification as well as circumvention of the available treatment facilities (Chiron and Minero 2007). The characteristic semi-volatility and lipophilicity of POPs encourages their widespread, environmental transportation and bioaccumulation respectively. A number of these compounds are chemically made up of carbonhalogen bonds which are very strong covalent bonds in form of an aromatic-chlorine or aromaticfluorine (Ministry of Environment and Water 2006). As a consequence of this, the compounds cannot be easily hydrolysed and therefore persist in the environment. Furthermore, their lipophilicity ensures passage through the lipid bilayer of the cell membrane and causes them to be locked up in the fatty tissue, where they may reach toxic concentrations (Tartu et al. 2017). Examples are organo-halogens which can be in the form of fluorinated compounds, hexachloro benzene, chlordane, dioxins, polychlorinated biphenyl (PCBs), mirex, furans, toxaphene, dichloro diphenyl trichloroethane (DDT) and heptachlor. 


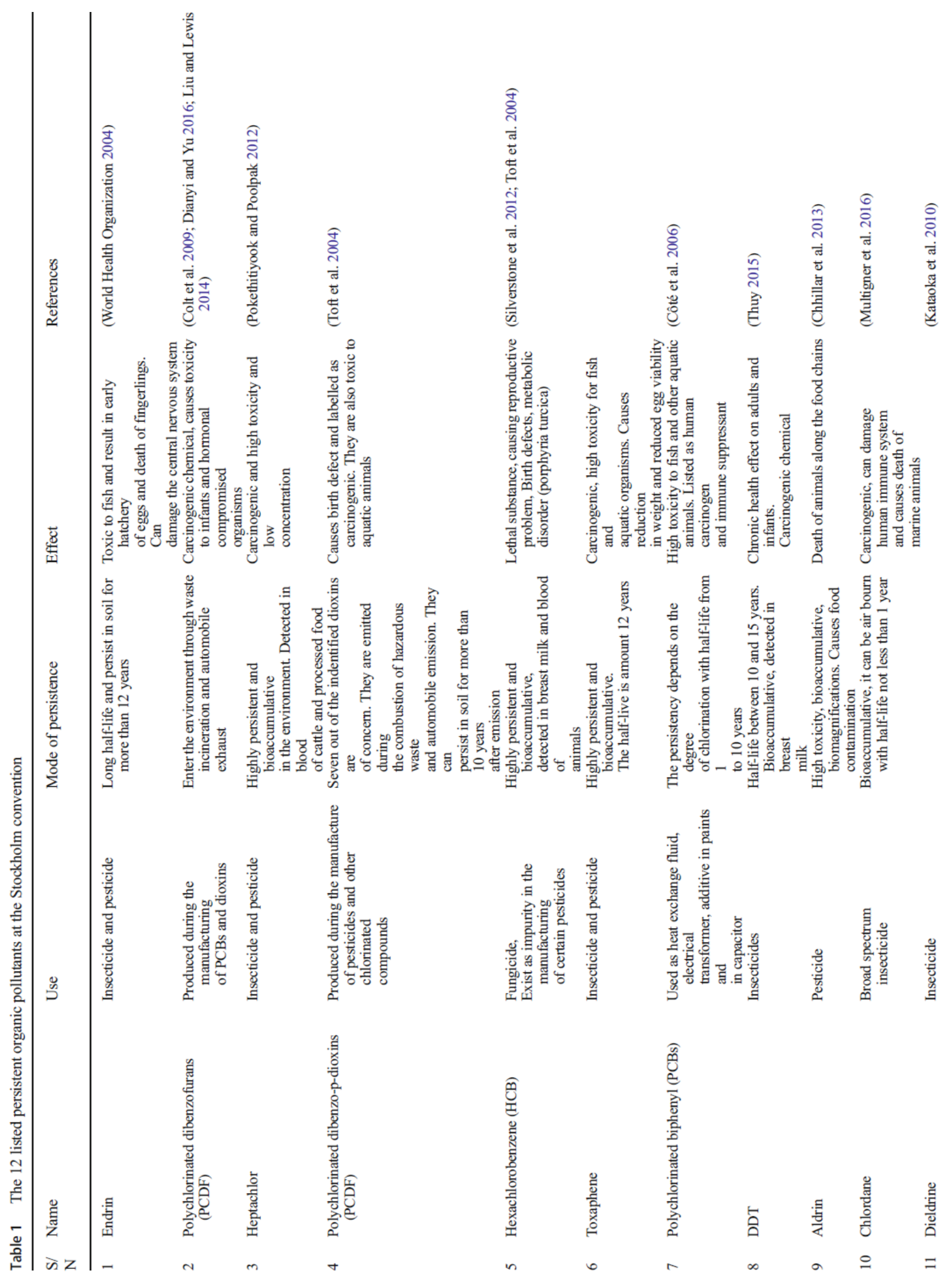

POPs are generated by both anthropogenic and non-anthropogenic activities with a significant proportion from the latter (Miniero and L'lamiceli 2008). The route of these chemicals depends on human uses, the media of transportation, physical and chemical 
properties. Primarily, POPs exposure is through water and consumption of contaminated food, especially sea food such as fish. Efficient treatment facilities must however be installed to properly remove the POPs in wastewater and ensure their absence in potable water.

\section{Treatment options}

Contaminated water contains hazardous chemicals and toxins which cause diseases and organ disruption. Water for human and animal use must be treated to ensure good health. Besides, transformation of contaminants into harmless end products and complying with legal approval for discharge is very important. Wastewater treatment methods ensure removal of the undesirable components from water and its conversion into a potable form which is free of waterborne pathogens and other hazardous compounds. Water treatment methods can be categorised into physical, chemical and biological treatment. Efficiency in wastewater treatment can most likely be achieved with the prudent combinations of two or more of these methods. Conventional treatment is the term that covers some of the successful water treatment techniques deployed in the service and provision of industrial or municipal potable water. Any of the physical, chemical or biological routes can be combined at the different stages of a particular conventional treatment technology. The stages in conventional wastewater treatment are generally referred to as preliminary, primary, secondary and tertiary, in increasing order of treatment level with the final $\mathrm{pH}$ adjustment as necessary. The appropriate conventional method must be able to meet the recommended microbiological and chemical standards set by the regulatory authority at an inexpensive operational and maintenance cost (M.B. Pescod 2004). Conversely, the regulatory agencies have not yet included limits for most of the POPs in their specifications for drinking water quality. POPs are however resistant to conventional treatment methods such as flocculation, coagulation, filtration and oxidant chemical treatment with chemicals like chlorine. They are not likely

to adsorb on organic matter despite their documented lipophilicity and application of treatment chemicals often leads to the formation of unwanted intermediates (Benitez et al. 2001). However, various advanced wastewater treatment technologies such as activated carbon adsorption, membrane bioreactor (MBR) and advanced oxidation processes (AOP) have been applied in the treatment of POPs (Kasprzyk-Hordern et al. 2009; Suárez et al. 2008). 


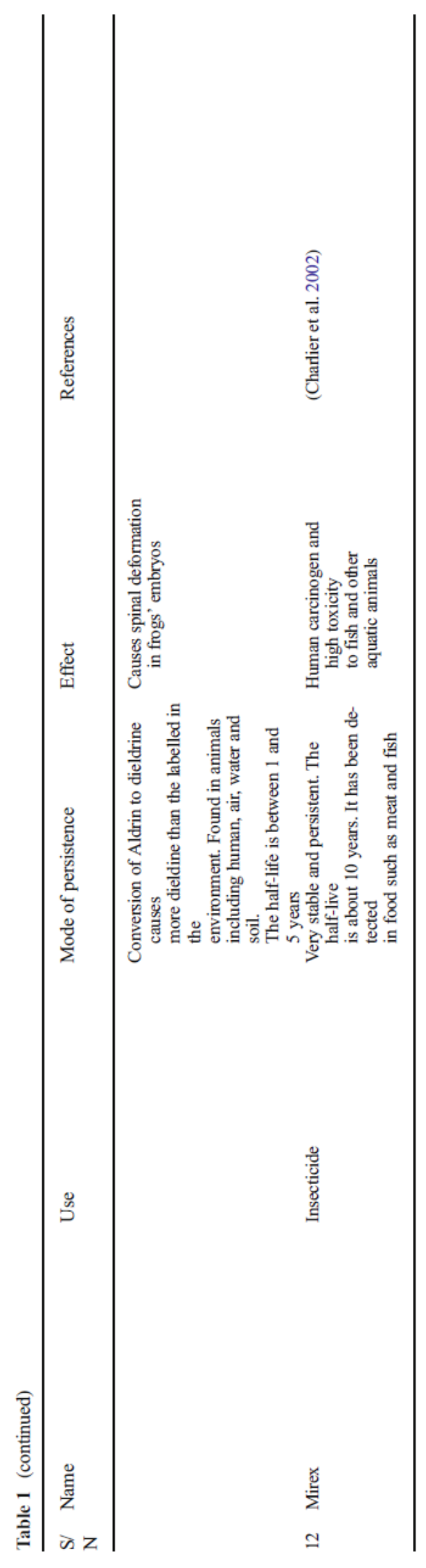




\section{Activated carbon adsorption}

Activated carbon is an extremely porous material with large surface area that allows the adsorption of a number of substances in their gaseous or liquid phases. Activated carbon can be used in commercial industries such as pharmaceuticals and foods for decolourisation, deodorisation and purification. It is capable of removing a large amount of dissolved compounds from wastewater because of its large surface area to volume ratio. The mechanism of removal is usually adsorption which occurs when the attractive forces on the carbon surface outweigh the attractive forces of the liquid. The large surface area of activated carbon accumulates large numbers of contaminant molecules. It is generally recommended in the tertiary stages of wastewater treatment for removal of chemical substances, colourants and reduction of COD. The activated carbon powder can be a form of granular activated carbon (GAC) or powdered activated carbon (PAC). The formation of toxic sludge, high maintenance cost and fouling of adsorbent material are their greatest limitation. Researching the use of low cost materials and surface functionalising has improved the use of activated carbon in water treatment (Dağdelen et al. 2014). Synthesis of activated carbon can be achieved through the use of waste carbonaceous substances or biomass. Üner et al. (2016) reported a significant removal of methylene blue (MB) dyes from aqueous solution using activated carbon synthesised from the activation of Citrullus lanatus (Melon) rind by zinc chloride. Altmann et al. (2014) in their direct comparison of activated carbon and ozonation for POPs treatment in wastewater reported the successful removal of carbamazepine and diclofenac by both treatment options. A greater efficiency was reported for activated carbon in the removal of bezafibrate, benzotriazole and iomeprol compared to ozone, while sulfamethoxazole was more efficiently removed by ozonation. However, each option has its own specificity, depending on the treatment objective. The use of activated carbon is very efficient and it may remove more than 90\% of the POPs, especially those that contain benzene and/or amine functionalities which enhance their sorption activity (Snyder et al. 2003). One of the advantages of GAC is the possibility of thermally reactivating and reusing of the carbon content. The PAC is usually added as dry powder or aqueous solution simultaneously with the flocculation step. PAC's economical advantages include reduction of cost due to aeration tanks and secondary settlement basins as well as its flexibility in term of dosing. Wong et al. (2016) reported the capability of triethoxyphenylsilane (TEPS)-functionalized magnetic palm-based powdered activated carbon (MPPACTEPS) for the low cost and effective degradation of POPs. Demerits are large volume of toxic sludge and the mere transfer of contaminants from aqueous phase to solid phase.

\section{Membrane bioreactor}

MBR is an integration of a biological process (such as a suspended growth reactor) with a perm-selective membrane. The solid material which is developed by biological process is preferentially rejected by a membrane to create a clarified and disinfected product. It is usually an active sludge with membrane filtration equipment based on ultra filtration or micro-filtration. MBR systems can be a gravity-driven or pressure-driven type. The gravity-driven systems involve the use of hollow fibres or flat sheet membranes in 
either the bioreactor or in a subsequent membrane tank while a pressure-driven system uses in-pipe cartridges located externally to the reactor. Generally, the process is initiated by a microbial degradation of the pollutants, followed by continuous filtration and air scouring in a series of working membrane units. The type of membrane is generally dependent on the size of the contaminant. It incorporates a series of filters such as nano-filters; used for contaminant sizes in the range 1 to $5 \mathrm{~nm}$, ultra-filters; used for contaminant sizes in the range 5 to $100 \mathrm{~nm}$ and micro-filtration which is used for contaminants of size ranges between 100 to $1000 \mathrm{~nm}$. MBR is considered efficient, simple, cost effective and reliable for the treatment of both organic and inorganic pollutants (Trzcinski and Stuckey 2016). It generates a high quality effluent. However, fouling of membranes which leads to the increase in trans-membrane pressure (TMP), processing time and cost of maintenance are the greatest hindrances in the application of MBR for wastewater treatment (Snyder et al. 2003). Likewise, generation of solid phase effluents which are very difficult to dispose is also a serious demerit associated with MBR. More research is desirable in order reduce the fouling effect and improve the integration of MBR in hybrid with treatment technologies for the increase exploitation of its many benefits (Mahamuni and Adewuyi 2010). Currently, the MBR do not always produce the expected result in the treatment of POPs and show poor removal of non-biodegradable aliphatic and aromatic hydrocarbon compounds, halogenated organic compounds, organic dyes, pesticides, phenols and their derivatives. The two most important assessment parameters for satisfaction of the objective in wastewater treatment technology are the process technicalities and economical feasibilities (Ozonek and Lenik 2011). An efficient, safe, low energy and cost-effective option must be exploited for effective treatment of highly persistent chemical compounds. Consequently, other important modern techniques currently undergoing intensive investigations must be exploited.

\section{Advanced oxidation processes}

AOPs are aqueous phase oxidation systems that generate highly reactive hydroxyl $(\mathrm{OH})$ radicals as the predominant species with high capabilities for destruction of persistent organic pollutants. The $\mathrm{OH}$ radicals ensure the effective degradation of soluble organic contaminants into simple and biodegradable forms. Factors such as water turbidity, solution $\mathrm{pH}$, time of reaction, amount/volume of the organic compound susceptible to degradation and the presence of $\mathrm{OH}$ radical scavengers or stimulator substances can significantly affect the degradation activity of the $\mathrm{OH}$ radical (Bethi et al. 2016). The AOPs can be in the form of an electrical discharge (ED) oxidation or a cavitation system, both of which are recently acknowledged as wastewater treatment technologies (Chong et al. 2012). The uniqueness of these processes is their diverse production of highly reactive $\mathrm{OH}$ radicals, which react nonspecifically and rapidly oxidise organic pollutants in wastewater. AOPs can be applied as a single process or in combination with other AOPs or with conventional methods depending on the treatment objectives and the properties of the wastewater stream. The most successful chemical so far used in AOPs is ozone, or its combinations such as $\mathrm{O}_{3} / \mathrm{H}_{2} \mathrm{O}_{2}, \mathrm{O}_{3} / \mathrm{UV}$ or $\mathrm{O}_{3} / \mathrm{Fe}_{2} \mathrm{O}_{3}$ (Shah et al. 2013). Shah et al. (2013) evaluated the degradation of acetaldehyde and amine in $\mathrm{O}_{3}, \mathrm{O}_{3} / \mathrm{H}_{2} \mathrm{O}_{2}$, or $\mathrm{UV} / \mathrm{H}_{2} \mathrm{O}_{2}$ AOPs systems. He reported that $\mathrm{OH}$ radical- 
based AOPs were more efficient than ozone in the destruction of acetaldehyde. Meanwhile, ozonation is considered to be a preferable treatment because it is more efficient for the destruction of amines and there is no need for the injection of hydrogen peroxide for optimum performance of the system. Giri et al. (2010) also confirmed the capability of ozonebased techniques for simultaneous removal of POPs when mineralising simulated wastewater containing 16 commonly used pharmaceuticals by using several combination AOP techniques. Despite the opportunities offered by ozone treatment of POPs, its toxicity, high cost of treatment and costly maintenance are big disadvantages. Besides, ozone performance is very poor in wastewater with high soluble solids (SS) content, high COD, high BOD or high TOC levels (Reis et al. 2012).

Hydrogen peroxide catalysed by $\mathrm{Fe}^{2+}$ in Fenton oxidation and Fenton-like processes has been highlighted to be successful in production of reactive hydroxyl radicals for the purpose of wastewater purification. The iron needed for catalytic oxidation in Fenton reactions is often available in industrial wastewater. Fenton oxidation can be applied in both primary and secondary stages of treatment. In this regards, the hydrogen peroxide catalysed by ferrous iron can disinfect the water, removing microorganisms while the $\mathrm{OH}$ radicals degrade the persistent organic pollutants and the generated $\mathrm{Fe}^{3+}$ complex acts as an excellent coagulant (Hamamoto and Kishimoto 2016). Conversely, difficulties in its conveyance and cost of hydrogen peroxide have been the greatest limitation in the application of Fenton oxidation. However, electro-Fenton systems with capabilities for in situ generation of $\mathrm{OH}$ radicals have been very successful in wastewater treatments in AOPs (Asghar et al. 2015). Factors such as initial concentration of the effluent stream, $\mathrm{pH}$, temperature, operating parameters (inlet pressure) and reactor design play vital roles in the determination of the process efficiency (Badmus et al. 2016). All these factors are very important and must be applied at the specific optimum conditions. The free radical generation process is $\mathrm{pH}$ sensitive and a good understanding of its manipulation is required for the successful degradation of POPs (Bagal and Gogate 2014a). Slow degradation can occur due to a low production rate of $\mathrm{OH}$ radicals in an acidic solution $(\mathrm{pH}<2.0)$. This can be caused by stabilisation of hydrogen peroxide due to the formation of oxonium ions at low $\mathrm{pH}$, or the formation of a slow reacting aqueous iron complex or the scavenging effect of hydrogen peroxide by the excess protons. Besides, Fe II complexes may be produced at $\mathrm{pH}>4$, this also reduces the production rate of the $\mathrm{OH}$ radical and consequently slows the degradation of POPs (Muruganandham et al. 2014; UNESCO 2012). The concentration of hydrogen peroxide must be optimised in order to prevent its excessive scavenging of $\mathrm{OH}$ radicals (Dimitrakopoulou et al. 2012; Gore et al. 2014). These highlighted challenges can be redressed with the deployment of novel cavitation technology and nano zero valent iron (nZVI) in the treatment of wastewater. The in situ generation of $\mathrm{OH}$ radical/hydrogen peroxide in cavitation technology and nZVI system has been recently reviewed (Lester et al. 2011). Either energy intensive UV or chemical intensive hydrogen peroxide can also be used to complement ozone or together in an AOP system to give efficient treatment of POPs. Dimitrakopoulou et al. (2012) investigated UV-A/TiO 2 photocatalytic degradation of amoxicillin (AMX) in aqueous suspension (Dimitrakopoulou et al. 2012). This system successfully degraded AMX in simulated wastewater, under the control 
of irradiation time, solution $\mathrm{pH}$, water matrix, photocatalyst types and loading. The degradation of the AMX was however very slow resulting in the formation of unknown intermediate products. A single AOP system can accomplish partial degradation of recalcitrant organic pollutants, but rarely achieves complete mineralisation except in combination with other forms of AOPs or treatment procedures (Cai et al. 2015; Hou et al. 2016; Zhang et al. 2013). Other challenges are the formation of unknown secondary by-products, costly chemical reagents (peroxide) and high energy requirement (UV and ultrasound). Since wastewater contains many chemical scavengers, a continuous flow of oxidants must therefore be ensured to achieve complete degradation or mineralisation of the contaminants. Efficient and low cost of treatment in AOPs can be achieved through the combined application of AOPs in a single system with potentially no or low chemical and energy inputs (Mahdad et al. 2015). This ensures synergistic effects, with the combined efficiency greater than the sum of individual efficiencies that could be achieved with a separate treatment (Table 2).

\section{Cavitation}

This is the formation, growth and collapse of bubbles (cavity) within a liquid as a consequence of local pressure pulsations. The liquid which contains vaporous bubbles experiences a consistent pressure reduction which results in the increase in size (growth) of bubbles and eventual collapse (implode) at a critical magnitude of pressure (Šarc et al. 2017). At this state, the critical pressure is lower or very close to the liquid specific saturated vapour pressure. The implosion of the bubble is accompanied with local destruction of chemical bonds, hydraulic shock, high temperature and pressure of about $5000 \mathrm{~K}$ and $60,000 \mathrm{kPa}$, respectively, for a short period in the trapped vapour (Gong and Hart 1998). Until recently, cavitation was only known for causing the erosion of metallic surfaces and research attention was on its prevention. Surface destruction and material displacement caused by cavitation have been huge challenges for mechanical equipment users and producer (Ozonek and Lenik 2011). Conversely, this extreme condition is adequate for rupture of biological or organic structures and dissociation of water molecules into $\mathrm{OH}$ and $\mathrm{H}$ radicals. The generated $\mathrm{OH}$ radical is an excellent initiator of chain reactions and one of the most powerful oxidants with the capability for spontaneous, non-specific degradation of unsaturated hydrocarbons. Since the unsaturated hydrocarbon bond is a basic chemical structure of organic contaminants, the generated $\mathrm{OH}$ radical can therefore be applied for the treatment of POPs in wastewater and sewage. Degradation of pollutants depends on their functional group content because only a small amount of radicals reach the bulk liquid bulk. Apparently, the $\mathrm{OH}$ radical is responsible for the degradation of organic pollutant during cavitation in three locations; inside the bubble, at the gas-liquid interface and in the bulk liquid phase (Mehrvar et al. 2001). The cavitation can be initiated by a local power supply as in optical (strong laser beam) and molecular cavitation (elementary particle) or by stretching forces, as in acoustic and hydrodynamic cavitation. The sizes of bubbles and their position can be controlled in both optical and molecular cavitation. Their commercial application is limited due to the high operational cost (Santos and Lodeiro 2009). The acoustic cavitations and hydrodynamic are the two most used types of cavitation technology with capability for large-scale application in wastewater treatment plants. Acoustic cavitation is caused by the acoustic waves in liquid while hydrodynamic cavitation is caused by hydrodynamic phenomena in liquid. Other existing cavitations are optical

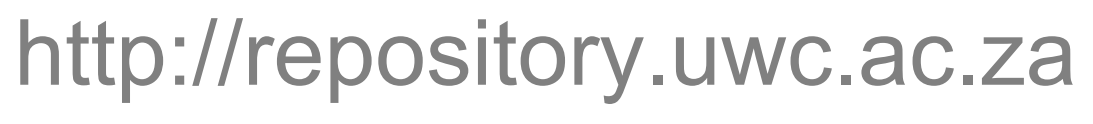


cavitation and molecular cavitation caused by strong laser beam and elementary particles (proton), respectively (Ozonek 2012).

Acoustic cavitation using ultrasound is a physical phenomenon which is caused by sound waves in alternating compression and rarefaction. The performance of ultrasonic cavitation depends upon the frequency, intensity of the sound waves, as well as temperature, the nature of solvent and the external pressure (Santos and Lodeiro 2009). The formation of bubbles in an ultrasonicator may be favoured at low frequencies $(20 \mathrm{kHz})$ because the higher the frequency the lower the cycle of compression and decompression. Therefore, the void needed for achievement of cavitation is absent at higher frequencies (Šarc et al. 2017). Conversely, an increase in sonochemical intensity can be caused by an increase in the amplitude of vibration. This is due to the proportional relationship between the amplitude and intensity. The intensity must be at the optimum value for achieving a positive sonochemical effect because too high an intensity may be detrimental to sonochemical degradation, leading to the deterioration of the transducer. Furthermore, optimum application of temperature must be ensured during ultrasonic cavitation. Too high temperatures can lead to disruption of the solute-matrix interaction, promote microbial integration and enhance the diffusion rate. The consequence of this is the reduction in sonication effect because increased evaporation leads to reduced bubble formation and successful bubble collision (Santos and Lodeiro 2009). Besides, cavitation is not easily achieved in a liquid of high natural cohesion, i.e., high magnitude of viscosity and surface tension (Webb et al. 2011). Atmospheric pressure is very adequate for ultrasonic cavitation. The pressure can be generated either through an ultra-sonic bath or probe by manipulating parameter such as the amplitude or frequency. These pressure pulse parameters are easy to control and reproduce. Consequently, acoustic cavitation is the best way to demonstrate the phenomenon of cavitation in the laboratory (Louisnard and González-garcía 2011). It can be applied directly using an ultrasonic probe or indirectly through the wall of the container using a sonication bath or sonoreactor. The unifying factor is the production of oxidative species, like hydroxyl radicals which invariably react with contaminants. According to hot-spot theory, reaction with free radicals can occur in the surrounding liquid, within the collapsing bubble and at its interface (Mahamuni and Adewuyi 2010). Ultrasonic applications are currently limited to laboratory scale and developing stage. However, they are increasingly gaining acceptance in the treatment of POPs in wastewater because of their environmental friendliness and cost effectiveness. The different types of probe can be immersed in a liquid directly for the purpose of sonication. Contamination and lose of volatile sample content are usually experienced as a consequence of direct contact of the probe with the liquid. The indirect application of sonication (glass probe) can take care of the contamination defect associated with the direct use of a probe (Santos and Capelo 2007; Santos and Lodeiro 2009). Ultrasonicator can be applied in wastewater decontamination, electrocoagulation, disinfection and membrane filtration (Sillanpää et al. 2011). 


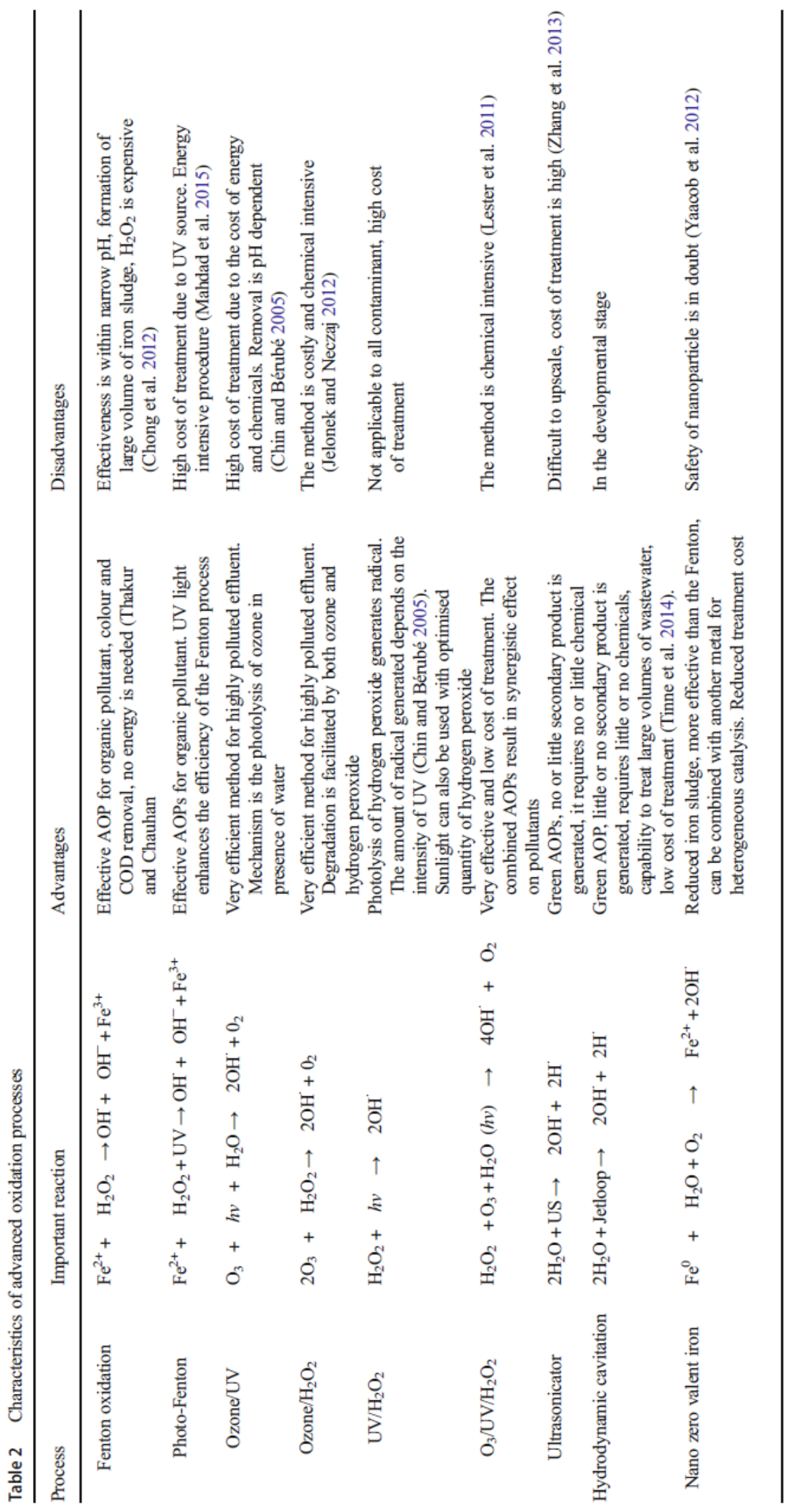

http://repository.uwc.ac.za 
The beneficial removal of several POPs by ultrasonication has been demonstrated in many studies (Bremner et al. 2010). Adewuyi and Khan (2012) provided a framework model for robust and rigorous development of sonochemical systems and reactors (Adewuyi and Khan 2012). Effective mineralisation of POPs, however, depends on the combination of ultrasonicator with other AOPs (de Vidales et al. 2015).

The cavity in hydrodynamic cavitation is generated as a consequence of constrictions in liquid flow. The smooth convergence/divergence of a venturi design ensures that the greatest degree of degradation could be obtained (venturi) compared to an orifice designed with similar levels of operating pressure (Mishra and Gogate 2010). The possibility of multiple holes within the same cross-sectional area and simple fabrication are the comparative advantages of using an orifice plate. The efficiency of hydrodynamic cavitation depends on the cumulative effect of factors such as device parameters, properties of the investigated velocity at the expense of pressure in a reactor. For hydrodynamic cavitation, orifice or venturi designs are capable of generating cavitation in a flowing liquid system and technology process parameter (Ozonek 2012). Device parameters such as the size or shape of the cavitation inducer and flow chamber defines the structural characteristics of the reactor while properties of the investigated system such as viscosity, density, dissolved gas and surface tension are the parameters characterising the properties of the medium. The technology process parameters are the liquid flow rate, temperature and inlet pressure. The lower the cavitation number, the higher the magnitude of velocities existing in a reactor and consequently the number of passes through the cavitating zone for the same time of operation will be higher (Dular et al. 2016). Therefore, higher degradation of pollutants is as a result of the high number of passes through the cavitating device which ensures that the liquid experiences cavitating conditions more frequently. The operating pressure in hydrodynamic cavitation is due to the high variation in liquid or fluid acceleration/deceleration inside a closed pipe. The inflexible experimental procedures of hydrodynamic cavitation create difficulties in its optimisation (Benito et al. 2005). Conversely, the operating cost is relatively low and the possibility of treating large volume of wastewater with inexpensive component parts such as tank, venturi tube and pipes is feasible.

Generally, cavitation is used as a post treatment procedure. It is usually applied after the treatment with biological processes or in combination with other advanced oxidation processes. The combination of cavitation with other AOP methods during wastewater treatment is to compensate for the challenges of each of the methods with regard to the mineralisation of POPs. In such cases, cavitation methods are very effective if carefully applied. Braeutigam et al. (2012) reported 63\% transformation of carbamazepine (5 $\mu \mathrm{g} / \mathrm{L})$ in a combined hydrodynamic cavitation and ultrasonic cavitation processes within 15 min. Zupanc et al. (2013) studied the removal of clofibric acid, ibuprofen, naproxen, ketoprofen, carbamazepine and diclofenac by hydrodynamic cavitation. They obtained between 30 and $70 \%$ degradation when their system was combined with $\mathrm{UV} / \mathrm{H}_{2} \mathrm{O}_{2}$ at optimum conditions. The two methods of cavitation (acoustic and hydrodynamic) are very efficient, green and cost effective for the treatment in wastewater, especially in the tertiary 
application to remove or mineralise POPs. Worthy of note is the advantageous edge of hydrodynamic (jet-loop) over acoustic (ultrasonicator) in terms of simplicity, energy efficiency (except multiple frequency flow cell), cost and large-scale application (Capocellia et al. 2014).

\section{Application of hydrodynamic cavitation in hybrid AOP systems}

Hydrodynamic cavitation at optimum operational conditions establishes the continuous generation of free radicals and allows the maximum contact between the generated radicals and the pollutants in the shortest possible time. Apparently, energy efficiency of hydrodynamic cavitation is highly dependent on experimental conditions and pollutant characteristics (Capocelli et al. 2014). Its various advantages such as low operational cost, no chemical addition, low energy utilisation and treatment of large volume of pollutants makes it a very efficient procedure for the mineralisation of POPs in partially treated water (Dular et al. 2016). The combination of hydrodynamic cavitation with other advanced oxidation processes ensure efficient mineralisation of micro-pollutants with better synergistic effects compared to stand-alone advanced oxidation processes (Gore et al. 2014 ). Khanchandani et al. (2016) reported effective degradation of methomyl using hydrodynamic cavitation and enhanced the treatment by combining it with other AOPs such as $\mathrm{H}_{2} \mathrm{O}_{2}$, Fenton reagent and ozone (Raut-jadhav et al. 2016). In their studies, hydrodynamic cavitation-ozone combination gives the highest mineralisation and energy efficiency among all the tested hybrid methods. Therefore, one or more of the popular AOPs such as ozone oxidation, Fenton process, photocatalytical oxidation, UV oxidation and recently zero valent iron application can be combined in hybrid AOPs for better treatment and elimination of associated disadvantages of a single treatment method.

\section{Photocatalysts and hydrodynamic cavitation}

Semiconductor photocatalysts such as $\mathrm{TiO}_{2}, \mathrm{SeO}_{2}$ and $\mathrm{ZnO}$ can absorb a substantial quantity of (UV) radiation from a light source (greater than its band gap) and generate an electron/hole pair. The generated negative electrons are capable of using the available excess energy to gain promotion (excitation) from the valence band (VB) to the conduction band (CB) and therefore leave behind positive holes (Fig. 1). The holes break down water molecules into hydrogen and hydroxyl radicals as the electrons react with oxygen to produce the super oxide anion $\left(\mathrm{O}^{-}{ }_{2}\right)$. Both radicals and superoxides are capable of reacting with POPs to generate more biodegradable end products (Khan et al. 2015a, b). The mechanism of POPs degradation may be through absorption of light by the photocatalyst and charge transfer reaction to create radical species for decomposition of adsorbed pollutants. Photocatalysts can either be homogenous or heterogeneous. The common challenges associated with photocatalysts are their high band gabs, agglomeration, small surface areas, instability and difficult recovery after treatment (Rehman et al. 2009). Techniques such as modification by organic materials, semi-conductor coupling and metal doping have been deployed by researchers to reduce the band gap and ensure the utilisation of lower energy (sourced from sunlight) by these photo active semi-conductors (Rehman et al. 2009). The capability for utilisation of natural resources such as sunlight, activity at room temperature and pressure, 
chemical stability and low cost of titania as well as it total mineralisation of a variety of organic pollutants are advantages of photocatalytic degradation using titanium(iv) oxide. However, the degradation of pollutants depend on physicochemical properties of the metal oxide, the amount of pollutants, the nature of the pollutant, its volume, the surface area of photocatalysts and the solution $\mathrm{pH}$ (Kaur and Singh 2007). Fouling of the photocatalysts and the presence of many radical scavengers will lower the rate of degradation and render the process ineffective in wastewater treatment, except when applied in combination with other AOPs. The simultaneous application of cavitation and photo catalytic oxidation has been reported to be a very effective method of contaminant degradation in wastewater treatment (Kavitha and Palanisamy 2011). The combination of hydrodynamic cavitation with $\mathrm{UV} / \mathrm{TiO}_{2}$ has been successfully applied in the laboratory scale degradation of diclofenac sodium, resulting in enhanced rates of degradation under optimised condition compared to the stand alone single treatment options using the two processes separately (Bagal and Gogate 2014b). Likewise, degradation (sonophotocatalytic oxidation) of reactive blue 19 ( $\mathrm{RB}$ 19) dye was successfully carried out using sulphur-doped $\mathrm{TiO}_{2} \quad\left(\mathrm{~S}^{-\mathrm{TiO}_{2}}\right)$ nanoparticles, sonolysis and sunlight. Khan et al. (2015a, b) demonstrated the possibility of reducing the band gap in $\mathrm{TiO}_{2}$ for the utilisation of visible light. However, the degradation rate depended on factors such as the initial concentration of blue 19 (RB 19) dye, the catalyst dosage, the ultrasonic power and the amount of sulphur doping. In spite of the reported successful cases of modification of $\mathrm{TiO}_{2}$ for its utilisation in visible light, commercial photocatalyst composites remain an illusion. It is therefore imperative that poor environmental and thermal stability of the photocatalyst must be resolved along with the formation of an excellent composite for photo degradation (Zangeneh et al. 2015).

\section{Ozone and hydrodynamic cavitation}

Ozone oxidation is reputed for its success in removal of odour, colour, with disinfection and wastewater decontamination over a wide $\mathrm{pH}$ range. Advantages include high oxidation power $\left(\mathrm{E}^{\mathrm{O}}=+2.07 \mathrm{~V}\right)$, non-selectivity, environmental friendliness and ability to simultaneously react with unsaturated species in the polluted water (U.S. EPA. 1999). Ozone can achieve the splitting of large organic molecules into smaller, biodegradable materials without the addition of disinfection chemicals. The reaction with POPs can be via a direct pathway, which involves the direct reaction between ozone and the dissolved pollutant at $\mathrm{pH}<4$ or the indirect pathway, which is the generation of the $\mathrm{OH}$ radical through the decomposition of ozone in water and the subsequent reaction of the generated radical with the pollutant (Grande 2015). As a result of its capability to combine a selective process via direct ozone oxidation and an unselective process via radical oxidation, ozonation can effectively degrade several POPs compared to other type of AOPs (Wang et al. 2016). The resulting biodegradable waste can be dealt with in the biological secondary/tertiary treatment stage. The kinetic of POPs degradation in ozone is typically second order, i.e. first order for the ozone and first order for the POPs. The achievement of effective non-linear degradation in ozone oxidation is due to the combined selective and non-selective reactivity of ozone gas and hydroxyl radical respectively. The accelerated mineralisation in the ozone-combination AOPs compared with 
other combined AOPs may be due the productions of the two oxidants (ozone and hydroxyl radical) instead of hydroxyl radical only.

Consequently, ozonation can participate in the polymerisation of metastable organic substances leading to their enmeshment, direct precipitation, bridging or adsorption and subsequent removal (Santos et al. 2013). Ozone is best generated in situ using energy sources such as the electrolytic process or cheminuclear, high voltage corona discharge or UV light (at a wavelength less than $200 \mathrm{~nm}$ ). Corona discharge is the most efficient of all the in situ ozone generation techniques (Carocci et al. 2014). It involves the generation of ozone by passing air or oxygen across a narrowly spaced pair of high voltage electrodes (Carocci et al. 2014). It is advantageous to apply molecular oxygen rather than air in the corona discharge gap (Malik et al. 2015). The ozone is produced as a result of dissociation of oxygen into its radical form and subsequent recombination in a closed chamber. The in situ generation of ozone is possible through the EDs. This type of equipment has gained particular attention in pollution control and environmental remediation.

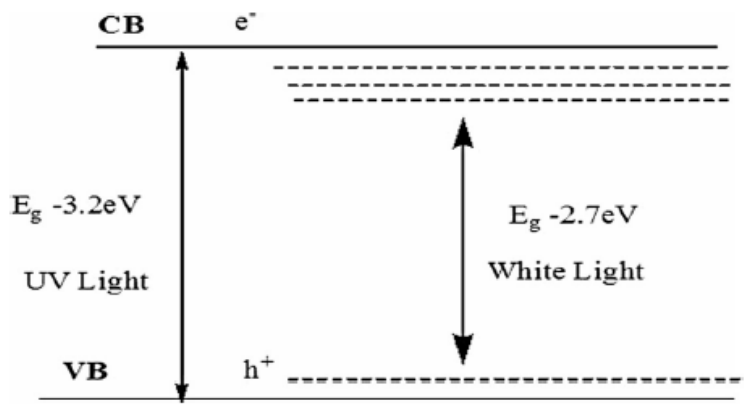

Fig. 1 Excitation of photocatalyst in UV and white light (CB represent the conduction band while VB represent the valency band)

Electric discharge is the channel of charged particles through a conductive material such as wire electrodes (Panorel 2013). This often results in the formation of an electrically neutral ionised gas referred to as plasma and known as the fourth state of matter. The term thermal plasma corresponds to high temperature and atmospheric pressure while nonthermal plasma (NTP) is referred to when the generation of free radicals is achieved at low temperature and atmospheric pressure. The generated energised electrons may cause a series of internal reactions and consequently the formation of free radicals. The formation of these oxidants in air or in aqueous systems follows consecutive mechanistic reaction chains that represent an in situ generated oxidative chemical mixture used for pollution control such as air cleaning (Xiao et al. 2014) or in surface sterilisation of polymers (Pankaj et al. 2014) or for the removal of contaminants in water and wastewater (Barkhudarov et al. 2013).

Ozone can also be used in hybrid combination with other AOPs for a better treatment option. Ozone assisted hydrodynamic cavitation hybrid system may enhance pollutants' oxidation significantly with reduction in the amount of ozone used, lowering the cost of treatment and energy demand (Ozonek 2012). The hybrid combination of hydrodynamic cavitation and ozone oxidation can synergistically eliminate the disadvantages associated with Bstand alone ${ }^{\wedge}$ processes and significantly improve the degradation output (Patil et al. 2014). 
Parag et al. (2015) reported that hydrodynamic cavitation-ozone hybrid is the best for the degradation of triazophos achieving $100 \%$ degradation in 90 min and TOC removal of 96\% (Gogate and Patil 2015). It has also been reported that the combined cavitationozonation oxidation process can change the molecular structures of organic matter and transform the non-biodegradable organics to more biodegradable forms (Korniluk and Ozonek 2013). Despite the significant degradation achievement of ozone hybrid processes in the treatment of persistent organic pollutants (Koutahzadeh et al. 2016), complications caused by the formation of toxic by-product and difficulty in up-scaling remain the subject of continue investigation (Grande 2015).

\section{Fenton oxidation and hydrodynamic cavitation}

Over a century ago, Fenton reported the oxidation of tartaric acid in the presence of a small quantity of ferrous salt (Haber and Weiss 1934). The produced solution from his reaction gave a violet colour on the addition of alkali. Apparently, this reaction which is popularly used today in water treatment was proposed by Fenton as an identification test for tartaric acid. The use of Fenton reagent in the degradation of organic pollutants has been widely reported (Babuponnusami and Muthukumar 2014; Sharma et al. 2011; Sychev and Isak 1995). It involves catalytical oxidation of hydrogen peroxide in the presence of $\mathrm{Fe}^{2+}$ to produce hydroxyl and other radicals that are responsible for degradation of POPs (i) to (iii).

$$
\begin{array}{llll}
\mathrm{Fe}^{2+}+\mathrm{H}_{2} \mathrm{O}_{2} & \rightarrow & \mathrm{Fe}^{3+}+\mathrm{HO}^{-} & \\
+\mathrm{HO}^{-} & & & \text {(i) } \\
\mathrm{Fe}^{3+}+\mathrm{H}_{2} \mathrm{O}_{2} & \rightarrow & \mathrm{Fe}-\mathrm{OOH}^{2+}+\mathrm{H}^{+} & \text {(ii) } \\
\mathrm{Fe}^{-} \mathrm{OOH}^{2+} & \rightarrow & \mathrm{Fe}^{2+}+\mathrm{HOO}^{\square} \text { (slow) } & \text { (iii) }
\end{array}
$$

The produced $\mathrm{Fe}^{3+}$ undergoes further reactions with hydrogen peroxide to regenerate $\mathrm{Fe}^{2+}$ and thereby established the catalytic role of the ferrous ion. The attractiveness of the Fenton process in the generation of $\mathrm{OH}$ radicals for treatment of persistent organic pollutants can be attributed to its cost effectiveness, the abundance and nontoxic nature of the resulting iron oxides as well as environmental friendliness of hydrogen peroxide (Sharma et al. 2011). Conversely, the narrow useful pH (2-3.5) range, consumption of large amounts of iron compounds, cost of peroxide and resultant formation of large amounts of iron sludge which are difficult to remove are the disadvantages of the Fenton process (Cui et al. 2014). Besides, the produced stable $\mathrm{Fe}^{3+}$-complexes may reduce the efficacy of the treatment method (Natalija et al. 2006). Overcoming these drawbacks is essential in the achievement of efficient treatment of POPs with Fenton oxidation.

\section{Hydrodynamic cavitation and nano zero valent iron}

The generation of in situ ferric iron and the chain of reactions due to the corrosion of metallic iron in an acidic condition is the term advanced Fenton process (AFP). Application of heterogeneous iron catalysts in the AFP offers a possibility of wider $\mathrm{pH}$ ranges $(\mathrm{pH} 2-9)$ and

\section{http://repository.uwc.ac.za}


lower amount of Fe sludge (Kwan and Voelker 2003). Unfortunately, $\mathrm{Fe}^{2+} / \mathrm{Fe}^{3+}$ rate of reaction in AFP is very low, causing a slow rate of reaction in the entire process (Wu et al. 2013). Developing efficient, reusable and durable heterogeneous Fenton catalysts that are active over a wide $\mathrm{pH}$ range is the subject of ongoing research (Araujo et al. 2011; Hou et al. 2016). The application of zero valent iron nanoparticle (nZVI) as a heterogeneous catalyst in an AFP has recently been reported. nZVI is very versatile and eliminates nearly all demerits associated with Fenton oxidation (Wang 2013; Zhang et al. 2013). In the nano form, the inherent desirable properties of a catalytic substance such as reactivity, photo-activity and selectivity can be enhanced. Environmental applications of nano iron materials include elimination of pollutants in wastewater treatment plants as well as site remediation. The application of nano iron particles has been highlighted in environmental remediation. The advantages include improved performance, lower energy consumption and reduction in residual waste (Ali et al. 2008). nZVI is an effective nano material for the mineralisation of a host of pollutants in contaminated water (Cao et al. 2011; Jewell and Wilson 2011; Yaacob et al. 2012). It is an ideal adsorbent with strong reducing capacity for contaminants such as organic dyes, persistent pollutant, halogens and heavy metals in wastewater treatment plants (Lopez-Telleza et al. 2011). A good number of publication have reported the degradation of persistent pollutants using nZVI in the treatment of contaminated water as a Bstand alone ${ }^{\wedge}$ wastewater treatment method (Sirk et al. 2009) or in combination with cavitation technology for the treatment of hydrocarbons in oil (Cui et al. 2014). Cavitation is capable of improving the performance of the heterogeneous catalyst in AFP by breaking down the stable $\mathrm{Fe}^{3+}$-complex and making the $\mathrm{Fe}^{3+}$ available for the regeneration of ferric ion. Cavitation combined with nZVI was found to significantly enhance the performance of AFP for mineralisation of organisms in waste-water in a hybrid combined AOP treatment (Chakinala et al. 2009). The excellent resultant mineralisation associated with this procedure and its successful application in real wastewater that containing varieties of $\mathrm{OH}$ radical scavengers is widely reported (Liang et al. 2007; Ma 2012). Cavitation-nZVI is a prospective hybrid process with significant capability for fast and efficient degradation of persistent organic pollutants. nZVI is a good source of heterogeneous iron catalyst for AFP. The Fenton-like chemistry reaction with hydrogen peroxide yielding a substantial amount of $\mathrm{OH}$ radical at a high reaction kinetic rate is shown in equation (iv) to (ix).

$$
\begin{gathered}
\mathrm{Fe}-\mathrm{OOH}^{2+}+\because \mathrm{Fe}^{2+}+\mathrm{HOO}^{\circ} \text { (fast) } \\
\mathrm{Fe}^{2+}+\mathrm{H}_{2} \mathrm{O}_{2}+\because \\
\mathrm{Fe}^{3+}+\mathrm{H}_{2} \mathrm{O}+\mathrm{Fe}^{3+}+\mathrm{HO}^{-}+\mathrm{HO}^{\circ} \\
\mathrm{Fe}^{0}+2 \mathrm{H}_{2} \mathrm{O}+\mathrm{Fe}^{2+}+\mathrm{H}^{+}+\mathrm{HO}^{\circ} \\
2 \mathrm{Fe}^{0}+\mathrm{O}_{2}+2 \mathrm{H}_{2} \mathrm{O}+\mathrm{Fe}^{2+}+\mathrm{H}_{2}+2 \mathrm{HO}^{\circ} \\
\mathrm{F}^{\circ} \rightarrow \mathrm{Fe}^{2+}+\mathrm{H}_{2}+2 \mathrm{HO}^{\circ}
\end{gathered}
$$


This process integrates fast degradation of POPs by nZVI with the role of generated $\mathrm{Fe}^{2+} / \mathrm{Fe}^{3+}$ in Fenton oxidation to achieve the desired output in the degradation of POPs. The initial reaction involves the oxidation of nZVI to yield $\mathrm{Fe}^{2+} / \mathrm{Fe}^{3+}$ which acts as catalyst in the Fenton production of $\mathrm{OH}$ radicals from the generated hydrogen peroxide. Both consumption of chemical reagents and production of large sludge can be significantly reduced in AFP using nZVI as the heterogeneous Fenton catalyst (Li et al. 2015). Although the research into wastewater treatment with hydrodynamic cavitation is still at the infant level, it offers a simple reactor design, inexpensive and less cumbersome operation procedures in comparison with acoustic cavitation (Gogate and Patil 2015). Besides, the associated disadvantages in the stand alone AOPs such as production of large quantity of iron sludge and narrow effective $\mathrm{pH}$ range (2-3.5) in the Fenton process (Cui et al. 2014) as well as lower mineralisation rate in hydrodynamic cavitation are completely eradicated in this hybrid combination of the two (Gogate and Patil 2015). Chakinala et al. (2008) proved that the combination of hydrodynamic cavitation and the Fenton process is capable of achieving about $80 \%$ reduction in TOC after an hour of treatment time (Chakinala et al. 2009). The efficacy of p-nitrophenol degradation in the hydrodynamic cavitation-Fenton hybrid system was found to be strongly dependent on the operating $\mathrm{pH}$ and it is at optimum at a $\mathrm{pH}$ of 3.75 (Pradhan and Gogate 2010). Pradhan and Gogate (2010) reported that the degradation efficiency for p-nitophenol degradation was dependent on the initial concentration of the pollutant (Pradhan and Gogate 2010). With 63.2\% degradation for $5 \mathrm{~g} / \mathrm{L}$ p-nitrophenol concentrated solution and $56.2 \%$ for $10 \mathrm{~g} / \mathrm{L}$, it can be argued that high initial concentrations give low percentage degradation rate while low initial concentrations result in high percentage degradation. Apparently, there is equivalence between the molecules of generated radicals and molecules of pollutants.

\section{Future perspective of cavitation process for POPs remediation}

The evidence supporting the contamination of wastewater by POPs and its negative consequences on humans and their immediate environment is overwhelming. It is a well known fact that the conventional water treatment facilities have failed to effectively degrade persistent contaminants from wastewater into their mineral form. However, established and advanced water treatment options such as activated carbons, membrane bioreactors and advanced oxidation processes are well documented for their capital intensive treatment of these recalcitrant pollutants. Technicality and economic feasibilities are important conditions in the choice of the prime technology for the removal of POPs in wastewater. Hybrid combination of hydrodynamic cavitation with any other suitable advanced oxidation process has demonstrated great capability and synergistic effect for degradation of POPs. Most of these hybrid methods are cost effective, simple, efficient, energy conserving and are commercially applicable. The associated demerits of a single oxidation process such as narrow $\mathrm{pH}$ range

\section{http://repository.uwc.ac.za}


are completely eliminated in the hybrid technologies. Notably, formation of large quantities of iron sludge in homogenous Fenton oxidation can also be eliminated by the hybrid combination of hydrodynamic cavitation and nZVI. The future of mineralisation of POPs in wastewater may be represented by hybrid combination of hydrodynamic cavitation and other suitable AOP as presented in this article. Following the outline reports, the future research would be focused on the mineralisation of POPs using optimised hydrodynamic cavitation system catalysed by the heterogeneous form of nano zero valent iron. This will ensure the reusability of the catalyst, reduction as well as easy removal of iron sludge and prevent leaching of nanoparticle in the treated water. 


\section{References}

Adewuyi YG, Khan NE (2012) Modeling the ultrasonic cavitation-enhanced removal of nitrogen oxide in a bubble column reactor. React Kinet Catal 58:2397-2411

Ali MG, Bastami TR, Ahmadpour A, Eshaghi Z (2008) Environmental application of nanotechnology. Annu Rev Nano Res 2:439-493

Altmann J, Ruhl AS, Zietzschmann F, Jekel M (2014) Direct comparison of ozonation and adsorption onto powdered activated carbon for micropollutant removal in advanced wastewater treatment. Water Res 55:185-193. https://doi.org/10.1016/j.watres.2014.02.025

Araujo FVF, Yokoyama L, Teixeira LAC, Campos JC (2011) Heterogeneous Fenton process using the mineral hematite for the discolouration of a reactive dye solution. Braz J Chem Eng 28:605- 616

Asghar A, Raman AAA, Daud WMAW (2015) Advanced oxidation processes for in-situ production of hydrogen peroxide/hydroxyl radical for textile wastewater treatment: a review. J Clean Prod 87:826-838. https://doi.org/10.1016/j.jclepro.2014.09.010

Babuponnusami A, Muthukumar K (2014) A review on Fenton and improvements to the Fenton process for wastewater treatment. J Environ Chem Eng 2:557-572

Badmus KO, Tijani JO, Eze CP, Fatoba OO, Petrik LF (2016) Chemistry quantification of radicals generated in a sonicator

Bagal MV, Gogate PR (2014a) Degradation of diclofenac sodium using combined processes based on hydrodynamic cavitation and heterogeneous photocatalysis. Ultrason Sonochem 21(3):1035-1043. https://doi.org/10.1016/j.ultsonch.2013.10.020

Bagal MV, Gogate PR (2014b) Wastewater treatment using hybrid treatment schemes based on cavitation and Fenton chemistry: a review. Ultrason Sonochem 21(1):1-14. https://doi.org/10.1016/j.ultsonch. 2013.07.009

Barkhudarov EM, Kossyi IA, Kozlov YN, Temchin SM, Taktakishvili MI, Christofi N (2013) Multispark discharge in water as a method of environmental sustainability problems solution. J At Mol Phys 2013:6-7

Benitez FJ, Acero JL, Real FJ, Rubio FJ, Leal AI (2001) The role of hydroxyl radicals for the decomposition of p-hydroxy phenylacetic acid in aqueous solutions. Water Res 35(5):1338-1343. https://doi. org/10.1016/Soo43-1354(0o)oo364-X

Benito Y, Arrojo S, Hauke G, Vidal P (2005) Hydrodynamic cavitation as a low-cost AOP for wastewater treatment: preliminary results and a new design approach. WIT Trans Ecol Environ 80:495-503

Bethi B, Sonawane SH, Rohit GS, Holkar CR, Pinjari DV, Bhanvase BA, Pandit AB (2016) Investigation of $\mathrm{TiO} 2$ photocatalyst performance for decolorization in the presence of hydrodynamic cavitation as hybrid AOP. Ultrason Sonochem 28:150-160. https://doi.org/10. 1016/j.ultsonch.2015.07.008

Braeutigam P, Franke M, Schneider RJ, Lehmann A, Stolle A, \& Ondruschka B (2012) Degradation of carbamazepine in environmentally relevant concentrations in water by Hydrodynamic-Acoustic-Cavitation (HAC). Water Res 46(7):2469-2477

Bremner HD, Burgess EA, \& Chand R (2011) The chemistry of ultrasonic degradation of organic compounds. Curr Org Chem 15(2):168-177 
Cai M, Su J, Zhu Y, Wei X, Jin M, Zhang H, Dong C, Wei Z (2015) Decolorization of azo dyes Orange $\mathrm{G}$ using hydrodynamic cavitation coupled with heterogeneous Fenton process. Ultrason Sonochem 28:302-310

Cao D, Niu KY, Yu F (2011) Economic analysis on pollution control for textile industry. Adv Mater Res 332-334:1087-1092

Capocelli M, Prisciandaro M, Lancia A, Musmarra D (2014) Application of ANN to hydrodynamic cavitation: preliminary results on process efficiency evaluation. Chem Eng Trans 36:199-204

Capocellia M, Prisciandarob M, Lanciac A (2014) Comparison between hydrodynamic and acoustic cavitation in microbial cell disruption. Chem 38:13-18

Carocci A, Rovito N, Sinicropi MS, \& Genchi G (2014) Mercury toxicity and neurodegenerative effects. In Reviews of environmental contamination and toxicology. Springer International Publishing, pp 1-18

Chakinala AG, Gogate PR, Burgess AE, Bremner DH (2009) Industrial wastewater treatment using hydrodynamic cavitation and heteroge- neous advanced Fenton processing. Chem Eng J 152(2-3):498-502. https://doi.org/10.1016/j.cej.2009.05.018

Chakinala AG, Gogate PR, Burgess AE, Bremner DH (2008) Treatment of industrial wastewater effluents using hydrodynamic cavitation and the advanced Fenton process. Ultrasonics sonochemistry 15(1):49-54

Charlier C, Desaive CL, Plomteux G (2002) Human exposure to endocrine disrupters: consequences of gastroplasty on plasma concentration of toxic pollutants. Int $\mathrm{J}$ Obes Relat Metab Disord 26(11):1465- 1468. https://doi.org/10.1038/sj.ijo.0802144

Chhillar N, Singh NK, Banerjee BD, Bala K, Sharma D, Chhillar M (2013) Organochlorine pesticide levels and risk of Parkinson's disease in north Indian population. Neurology 2013:6

Chin A, Bérubé PR (2005) Removal of disinfection by-product precursors with ozoneUVadvanced oxidation process. Water Res 39(10): 2136-2144. https://doi.org/10.1016/j.watres.2005.03.021

Chiron S, Minero C (2007) Occurrence of 2, 4-dichlorophenol and of 2, 4-dichloro-6nitrophenol in the Rhone River delta (Southern France). Environ Sci Technol 41(9):3127-3133. https://doi.org/10. 1021/eso626638

Chong MN, Sharma AK, Burn S, Saint CP (2012) Feasibility study on the application of advanced oxidation technologies for decentralised wastewater treatment. J Clean Prod 35:230-238. https://doi.org/10. 1016/j.jclepro.2012.06.003

Clara M, Kreuzinger N, Strenn B, Gans O, Kroiss H (2005) The solids retention time-a suitable design parameter to evaluate the capacity of wastewater treatment plants to remove micropollutants. Water Res 39(1):97-106. https://doi.org/10.1016/j.watres.2004.08.036

Colt JS, Rothman N, Severson RK, Hartge P, Cerhan JR, Chatterjee N, Cozen W, Morton LM, De Roos AJ, Davis S, Chanock S, Wang SS (2009) Organochlorine exposure, immune gene variation, and risk of non-Hodgkin lymphoma. Blood 113(9):1899-1906. https://doi. org/10.1182/blood-2008-04-153858 
Corcoran E, Nellemann C, Baker E, Bos R, Osborn D, Savelli H (2010) Sick water? The central role of wastewater management in sustainable development. A rapid response assessment., United Nations Environment Programme, UN-HABITAT

Côté S, Ayotte P, Dodin S, Blanchet C, Mulvad G, Petersen HS, Gingras S, Dewailly E (2006) Plasma organochlorine concentrations and bone ultrasound measurements: a crosssectional study in peri- and postmenopausal Inuit women from Greenland. Environ Health 5(1): 33. https://doi.org/10.1186/1476-069X-5-33

de Vidales MJM, Sáez C, Pérez JF, Cotillas S, Llanos J, Cañizares P, \& Rodrigo MA (2015) Irradiation-assisted electrochemical processes for the removal of persistent organic pollutants from wastewater. J Appl Electrochem 45(7):799-808

Cui K, Yi H, Zhou Z-J, Zhuo Q-F, Bing Y-X, Guo Q-W, Xu Z-C (2014) Fenton oxidation kinetics and intermediates of nonylphenol ethoxylates. Environ Eng Sci 31(5):217224. https://doi.org/10. 1089/ees.2013.0308

Dağdelen S, Acemioğlu B, Baran E, Koçer O (2014) Removal of remazol brilliant blue R from aqueous solution by pirina pretreated with nitric acid and commercial activated carbon. Water Air Soil Pollut 225(3). https://doi.org/10.1007/s11270-014-1899-8

DEFRA (2012) Waste water treatment in the United Kingdom, implication of the European Union Urban Waste Water Treatment Directive-91/271/EEC

Dianyi, Yu M (2016) Case studies in environmental medicine polychlorinated biphenyls (PCBs) toxicity

Dimitrakopoulou D, Rethemiotaki I, Frontistis Z, Xekoukoulotakis NP, Venieri D, Mantzavinos D (2012) Degradation, mineralization and antibiotic inactivation of amoxicillin by UVA/TiO 2 photocatalysis. J Environ Manag 98:168-174. https://doi.org/10.1016/j.jenvman. 2012.01.010

Dular M, Griessler-Bulc T, Gutierrez-Aguirre I, Heath E, Kosjek T, Krivograd Klemenčič A, Oder M, Petkovšek M, Rački N, Ravnikar M, Šarc A, Širok B, Zupanc M, Žitnik M, Kompare B (2016) Use of hydrodynamic cavitation in (waste)water treatment. Ultrason Sonochem 29:577-588. https://doi.org/10.1016/j.ultsonch. 2015.10.010

Frenken K, and Gillet V (2012) Irrigation water requirement and water withdrawal by country. FAO, Rome, Italy

Giri RR, Ozaki H et al (2010) Degradation of common pharmaceuticals and personal care products in mixed solutions by advanced oxidation techniques[J]. Int $\mathrm{J}$ Environ Sci Technol 7:251-260

Gogate PR, Patil PN (2015) Combined treatment technology based on synergism between hydrodynamic cavitation and advanced oxidation processes. Ultrason Sonochem 25:60-69. https://doi.org/10. 1016/j.ultsonch.2014.08.016

Gong C, Hart DP (1998) Ultrasound induced cavitation and sonochemical yields. J Acoust Soc Am 104(5):2675-2682. https:// doi.org/10.1121/1.423851

Gore MM, Saharan VK, Pinjari DV, Chavan PV, Pandit AB (2014) Degradation of reactive orange 4 dye using hydrodynamic cavitation based hybrid techniques. Ultrason Sonochem 21(3):1075-1082. https://doi.org/10.1016/j.ultsonch.2013.11.015

Grande GA (2015) Treatment of wastewater from textile dyeing by ozonization. POLITECNICO DI TORINO 
Haber F, Weiss J (1934) The catalytic decomposition of hydrogen peroxide b y iron s alts [WW W Doc u ment]. http://rspa.royalsocietypublishing.org/

Hamamoto S, Kishimoto N (2016) Ce pt ed cr t. Sep Sci Technol 6395

Hossain MM, Islam KMN, Rahman IMM (2012) An overview of the persistent organic pollutants in the freshwater system. In: Ecological water quality-water treatment and reuse edited. pp 496

Hou X, Huang X, Ai Z, Zhao J, Zhang L (2016) Ascorbic acid/Fe@Fe2O3: a highly efficient combined Fenton reagent to remove organic contaminants. J Hazard Mater 310:170-178. https:// doi.org/10.1016/j.jhazmat.2016.01.020

Jelonek P, and Neczaj E (2012) The use of Advanced Oxidation Processes (AOP) for the treatment of landfill leachate. Inżynieria i Ochrona Środowiska 15:203-217

Jewell KP, Wilson JT (2011) Water level monitoring pressure transducers: a need for industrywide standards. Ground Water Monit Remediat 31(3):82-94. https://doi.org/10.1111/j.1745-6592.2011.01345.x

Khanchandani S, Kumar S, Ganguli AK (2016) Comparative study of $\mathrm{TiO}_{2} / \mathrm{CuS}$ core/shell and composite nanostructures for efficient visible light photocatalysis. ACS Sustainable Chemistry \& Engineering 4(3):1487-1499

Kasprzyk-Hordern B, Dinsdale RM, Guwy AJ (2009) The removal of pharmaceuticals, personal care products, endocrine disruptors and illicit drugs during wastewater treatment and its impact on the quality of receiving waters. Water Res 43(2):363-380. https://doi.org/10. 1016/j.watres.2008.10.047

Kataoka R, Takagi K, Kamei I, Kiyota H, Sato Y (2010) Biodegradation of dieldrin by a soil fungus isolated from a soil with annual endosulfan applications. Environ Sci Technol 44(16):6343-6349. https://doi.org/10.1021/es1000227

Kaur S, Singh V (2007) Visible light induced sonophotocatalytic degradation of reactive red dye 198 using dye sensitized TiO2. Ultrason Sonochem 14(5):531-537. https://doi.org/10.1016/j.ultsonch.2006.09.015

Kavitha SK, Palanisamy PN (2011) Photocatalytic and sonophotocatalytic degradation of Reactive Red 120 using dye sensitized TiO2 under visible light. Eng Technol 5:1-6

Khan MAN, Siddique M, Wahid F, Khan R (2015a) Removal of reactive blue 19 dye by sono, photo and sonophotocatalytic oxidation using visible light. Ultrason Sonochem 26:370-377. https://doi.org/10. 1016/j.ultsonch.2015.04.012

Khan MM, Adil SF, Al-Mayouf A (2015b) Metal oxides as photocatalysts. J Saudi Chem Soc 19:462-464

Kiparissis Y, Balch GC, Metcalfe TL, Metcalfe CD (2003) Effects of the isoflavones genistein and equol on the gonadal development of Japanese medaka (Oryzias Latipes). Environ Health Perspect 111(9):1158-1163. https://doi.org/10.1289/ehp.5928

Korniluk M, \& Ozonek J (2013) Investigation on landfill leachate biodegradability improvement by use of hydrodynamic cavitation and ozone. Rocznik Ochrona Środowiska 15(cz. 1):124-135

Koutahzadeh N, Esfahani MR, Arce PE (2016) Removal of acid black 1 from water by the pulsed corona discharge advanced oxidation method. J Water Process Eng 10:1-8 
Krapcheva S (2006) National Implementation Plan for the Management of Persistent Organic Pollutants (POPs) in the Republic of Bulgaria National Ministry of Environment and Water of the Republic of Bulgaria. MEOW, Sofia

Kwan WP, Voelker BM (2003) Rates of hydroxyl radical generation and organic compound oxidation in mineral-catalyzed Fenton-like systems. Environ Sci Technol 37(6):11501158. https://doi.org/10. 1021/es020874g

Lester Y, Avisar D, Gozlan I, Mamane H (2011) Removal of pharmaceuticals using combination of $\mathrm{UV} / \mathrm{H}_{2} \mathrm{O}_{2} / \mathrm{O}_{3}$ advanced oxidation process. Water Sci Technol 2:1-10

Li R, Jin X, Megharaj M, Naidu R, Chen Z (2015) Heterogeneous Fenton oxidation of 2,4dichlorophenol using iron-based nanoparticles and persulfate system. Chem Eng $\mathrm{J}$ 264:587-594. https://doi.org/10. 1016/j.cej.2014.11.128

Liang J, Komarov S, Hayashi N, Kasai E (2007) Improvement in sonochemical degradation of 4-chlorophenol by combined use of Fenton-like reagents. Ultrason Sonochem 14(2):201-207. https:// doi.org/10.1016/j.ultsonch.2006.05.002

Liu J, Lewis G (2014) Environmental toxicity and poor cognitive outcomes in children and adults. J Environ Health 76(6):130-138

Lopez-Telleza G, Barrera-Diaza CE, Balderas-Hernandeza P, Bilyeub (2011) Removal of hexavalent chromium in aquatic solutions by iron nanoparticles embedded in orange peel pith. Chem Eng J 173(2):480-485. https://doi.org/10.1016/j.cej.2011.08.018

Louisnard O, \& González-García J (2011) Acoustic cavitation. In Ultrasound technologies for food and bioprocessing. Springer, New York, pp 13-64

Ma Y (2012) Short review: current trends and future challenges in the application of sonoFenton oxidation for wastewater treatment. Sustain Environ Res 22:271-278

Mahamuni NN, Adewuyi YG (2010) Advanced oxidation processes (AOPs) involving ultrasound for waste water treatment: a review with emphasis on cost estimation. Ultrason Sonochem 17(6):990- 1003. https://doi.org/10.1016/j.ultsonch.2009.09.005

Mahdad F, Younesi H, Bahramifar N, Hadavifar M (2015) Optimization of Fenton and photoFenton-based advanced oxidation processes for post-treatment of composting leachate of municipal solid waste by an activated sludge process. KSCE J Civ Eng 0:1-12

Malik MA, Hughes D, Heller R, Schoenbach KH (2015) Surface plasmas versus volume plasma: energy deposition and ozone generation in air and oxygen. Plasma Chem Plasma Process 35(4):697-704. https://doi.org/10.1007/s11090-015-9611-3

Mehrvar M, Anderson WA, Moo-young M (2001) Photocatalytic degradation of aqueous organic solvents in the presence of hydroxyl radical scavengers. Int J Photoenergy 3(4):187-191. https://doi.org/10. 1155/S1110662X01000241

Miniero R, L'lamiceli A (2008) Persistent Organic Pollutants, Encyclopedia of Ecology Ministry of Environment and Water (2006) Basic characteristics of persistent organic polutants (POPS)

Mishra KP, Gogate PR (2010) Intensification of degradation of rhodamine B using hydrodynamic cavitation in the presence of additives. Sep Purif Technol 75(3):385-391. https://doi.org/10.1016/j.seppur. 2010.09.008

Multigner L, Kadhel P, Rouget F, Blanchet P, Cordier S (2016) Chlordecone exposure and adverse effects in French West Indies populations. Environ Sci Pollut Res 23(1):3-8. https://doi.org/10. 1007/s11356-015-4621-5 
Muruganandham M, Suri RPS, Jafari S, Sillanpää M, Lee G, Wu JJ, Swaminathan M (2014) Recent developments in homogeneous advanced oxidation processes for water and wastewater treatment. 2014:21. https://doi.org/10.1155/2014/821674

Natalija K, Iva SH, Hrvoje K (2006) Fe-exchanged zeolite as the effective heterogeneous Fenton-type catalyst for the organic pollutant minimization: UV irradiation assistance. Chemosphere 65:65-73

OECD (2011) OECD environmental outlook to 2050: the consequences of inaction, OECD environmental outlook to 2050. https://doi.org/ 10.1787/eco_outlook-v2011-sup1-en

Ozonek J (2012) Application of hydrodynamic cavitation in environmental engineering. Taylor \& Francis Group, LLC., 6000 broken Sound Parkway NW, suite 300 Boca Raton, FL 33487-2742

Ozonek J, Lenik K (2011) Effect of different design features of the reactor on hydrodynamic cavitation process. Arch. Mater Sci Eng 52:112- 117

Pandey PK, Kass PH, Soupir ML, Biswas S, Singh VP (2014) Contamination of water resources by pathogenic bacteria. AMB Express 4(1):51. https://doi.org/10.1186/s13568-014-0051-x

Pankaj SK, Bueno-Ferrer C, Misra NN, Milosavljević V, O’Donnell CP, Bourke P, Keener KM, Cullen PJ (2014) Applications of cold plasma technology in food packaging. Trends Food Sci Technol 35(1): 5-17. https://doi.org/10.1016/j.tifs.2013.10.009

Panorel IC (2013) Pulsed corona discharge as an advanced oxidation process for degradation of organic. Acta Universitatis Lappeenrantaensis

Patil PN, Bote SD, Gogate PR (2014) Degradation of imidacloprid using combined advanced oxidation processes based on hydrodynamic cavitation. Ultrason Sonochem 21(5):1770-1777. https://doi.org/ 10.1016/j.ultsonch.2014.02.024

Pescod MB (2004) Wastewater treatment and use in agriculture-FAO irrigation and drainage paper 47. Food and Agriculture Organization of United Nations

Pokethitiyook P, Poolpak T (2012) Chapter 11: heptachlor and its metabolite: accumulation and degradation in sediment. In Pesticides-Recent Trends in Pesticide Residue Assay. InTech. 217-252. https://doi.org/10.5772/48741

Pradhan AA, Gogate PR (2010) Removal of p-nitrophenol using hydrodynamic cavitation and Fenton chemistry at pilot scale operation. Chem Eng J 156(1):77-82. https://doi.org/10.1016/j.cej.2009.09. 042

Pradhan AA, Gogate PR (2010) Degradation of p-nitrophenol using acoustic cavitation and Fenton chemistry. Journal of hazardous materials 173(1):517-522. https://doi.org/10.1016/j.jhazmat.2009.08.115

Raut-jadhav S, Saini D, Sonawane S, Pandit A (2016) Ultrasonics sonochemistry effect of process intensifying parameters on the hydrodynamic cavitation based degradation of commercial pesticide (methomyl) in the aqueous solution. Ultrason Sonochem 28:283293. https://doi.org/10.1016/j.ultsonch.2015.08.004

Rehman S, Ullah R, Butt AM, Gohar ND (2009) Strategies of making TiO2 and $\mathrm{ZnO}$ visible light active. J Hazard Mater 170(2-3):560- 569. https://doi.org/10.1016/j.jhazmat.2009.05.064

Reis RM, Beati AAGF, Rocha RS, Assumpção MHMT, Santos MC, Bertazzoli R, Lanza MRV (2012) Use of gas diffusion electrode for the in situ generation of hydrogen peroxide in 
an electrochemical flow-by reactor. Ind Eng Chem Res 51(2):649-654. https://doi.org/ 10.1021/ie201317u

Santos HM, Lodeiro C, Capelo-Martínez JL (2008) Power ultrasound meets protemics. Ultrasound in chemistry: analytical applications: 107-127. https://doi.org/10.1002/9783527623501.ch5

Santos HM, Capelo JL (2007) Trends in ultrasonic-based equipment for analytical sample treatment. Talanta 73(5):795-802. https://doi.org/ 10.1016/j.talanta.2007.05.039

Santos HM, Lodeiro C (2009) The power of ultrasound:1-16

Santos DC, Silva L, Albuquerque A, Simões R, Gomes AC (2013) Biodegradability enhancement and detoxification of cork processing wastewater molecular size fractions by ozone. Bioresour Technol 147:143-151. https://doi.org/10.1016/j.biortech.2013.07.154

Šarc A, Stepišnik-Perdih T, Petkovšek M, Dular M (2017) The issue of cavitation number value in studies of water treatment by hydrodynamic cavitation. Ultrason Sonochem 34:5159. https://doi.org/10.1016/j.ultsonch.2016.05.020

Shah AD, Dai N, Mitch WA (2013) Application of ultraviolet, ozone, and advanced oxidation treatments to washwaters to destroy nitrosamines, nitramines, amines, and aldehydes formed during aminebased carbon capture. Environ Sci Technol 47(6):2799-2808. https://doi.org/10.1021/es304893m

Sharma S, Ruparelia JP, \& Patel ML (2011) A general review on Advanced Oxidation Processes for waste water treatment. In Nirma University International Conference, Ahmedabad, Gujarat

Sillanpää M, Pham TD, \& Shrestha RA (2011) Ultrasound technology in green chemistry. In Ultrasound Technology in Green Chemistry. Springer, Netherlands, pp 1-21

Silverstone AE, Rosenbaum PF, Weinstock RS, Bartell SM, Foushee HR, Shelton C, Pavuk M (2012) Polychlorinated biphenyl (PCB) exposure and diabetes: results from the Anniston community health survey. Environ Health Perspect 120(5):727-732. https://doi.org/10. 1289/ehp.1104247

Sirk KM, Saleh NB, Phenrat T, Kim H, Dufour B, Ok J, Golas PL, Matyjaszewski K, Llwry GV, Tilton RD (2009) Effect of adsorbed polyelectrolytes on nanoscale zero valent iron particle attachment to soil surface models. Environ Sci Technol 43(10):3803-3808. https:// doi.org/10.1021/es803589t

Snyder S, Westerhoff P, Yoon Y, Sedlak D (2003) Disruptors in water: implications for the water industry. Environ Eng Sci 20(5):449-469. https://doi.org/10.1089/109287503768335931

Suárez S, Carballa M, Omil F, Lema JM (2008) How are pharmaceutical and personal care products (PPCPs) removed from urban wastewaters? Rev Environ Sci Biotechnol 7(2):125-138. https://doi.org/10. 1007/s11157-008-9130-2

Sychev A, Isak V (1995) Iron compounds and the mechanisms of the homogeneous catalysis of the activation of $\mathrm{O}_{2}$ and $\mathrm{H}_{2} \mathrm{O}_{2}$ and of the oxidation of organic substrates. Russ Chem Rev 65:1105-1129

Tartu S, Bourgeon S, Aars J, Andersen M, Polder A, Thiemann GW, Welker JM, Routti H (2017) Science of the total environment sea ice-associated decline in body condition leads to increased concentrations of lipophilic pollutants in polar bears (Ursus

\section{http://repository.uwc.ac.za}


maritimus) from Svalbard, Norway. Sci Total Environ 576:409-419. https:// doi.org/10.1016/j.scitotenv.2016.10.132

Thuy TT (2015) Effects of ddt on environment and human health. J Educ Soc Sci 2:108-114

Tinne N, Kaune B, Kruger A, Ripken T (2014) Interaction mechanisms of cavitation bubbles induced by spatially and temporally separated fs-laser pulses. PLoS One 9:1-26

Toft G, Hagmar L, Giwercman A, Bonde JP (2004) Epidemiological evidence on reproductive effects of persistent organochlorines in humans. Reprod Toxicol 19(1):5-26. https://doi.org/10.1016/j. reprotox.2004.05.006

Trzcinski AP, Stuckey DC (2016) Inorganic fouling of an anaerobic membrane bioreactor treating leachate from the organic fraction of municipal solid waste (OFMSW) and a polishing aerobic membrane bioreactor. Bioresour Technol 204:17-25. https://doi.org/10.1016/j. biortech.2015.12.074

U.S. EPA (1999) Wastewater technology fact sheet ozone disinfection, Office of Water Washington, D.C

Üner O, Geçgel Ü, Bayrak Y (2016) Adsorption of methylene blue by an efficient activated carbon prepared from Citrullus lanatus rind: kinetic, isotherm, thermodynamic, and mechanism analysis. Water Air Soil Pollut 227(7):247. https://doi.org/10.1007/s11270016-2949-1

UNESCO (2012) Managing water under uncertainty and risk

Water UN (2012) Managing water under uncertainty and risk, The United Nations world water development report 4. UN Water Reports, World Water Assessment Programme

Wang Z (2013) Iron complex nanoparticles synthesized by eucalyptus leaves. ACS Sustain Chem Eng 1(12):1551-1554

Wang C, Klamerth N, Messele SA, Singh A, Belosevic M, Gamal El-Din M (2016) Comparison of UV/hydrogen peroxide, potassium ferrate(VI), and ozone in oxidizing the organic fraction of oil sands process-affected water (OSPW). Water Res 100:476-485. https:// doi.org/10.1016/j.watres.2016.05.037

Webb IR, Payne SJ, Coussios C (2011) The effect of temperature and viscoelasticity on cavitation dynamics during ultrasonic ablation. Acoust Soc Am 130(5):3458-3466. https://doi.org/10.1121/1. 3626136

Wong KT, Yoon Y, Snyder SA, Jang M (2016) Phenyl-functionalized magnetic palm-based powdered activated carbon for the effective removal of selected pharmaceutical and endocrine-disruptive compounds. Chemosphere 152:71-80. https://doi.org/10.1016/j. chemosphere.2016.02.090

World Health Organization (2004) Endrin in drinking water, endrin in drinking-water, background document for development of WHO Guidelines for Drinking-water Quality

Wu TY, Guo N, Teh CY, \& Hay JXW (2013) Theory and fundamentals of ultrasound. In Advances in Ultrasound Technology for Environmental Remediation. Springer, Netherlands, pp 5-12

Xiao G, Xu W, Wu R, Ni M, Du C, Gao X, Luo Z, Cen K (2014) Non-thermal plasmas for VOCs abatement. Plasma Chem Plasma Process 34:1033-1065

Yaacob WZW, Kamaruzaman N, Samsudin AR (2012) Development of nano-zero valent iron for the remediation of contaminated water. Chem Eng Trans 28:25-30 
Zangeneh H, Zinatizadeh AAL, Habibi M, Akia M, Hasnain Isa M (2015) Photocatalytic oxidation of organic dyes and pollutants in wastewater using different modified titanium dioxides: a comparative review. J Ind Eng Chem 26:1-36. https://doi.org/ 10.1016/j.jiec.2014.10.043

Zhang J, Li J, Thring R, Liu L (2013) Application of ultrasound and Fenton's reaction process for the treatment of oily sludge. Procedia Environ Sci 18:686-693

Zupanc M, Kosjek T, Petkovšek M, Dular M, Kompare B, Širok B, Blažeka Ž, Heath E (2013) Removal of pharmaceuticals from wastewater by biological processes, hydrodynamic cavitation and UV treatment. Ultrason Sonochem 20(4):1104-1112. https://doi.org/10.1016/j.ultsonch.2012.12.003 